\title{
STRUCTURAL, ELECTRONIC AND VIBRATIONAL STUDY OF 4, 6-DICHLORO-5- METHYLPYRIMIDINE: A DFT APPROACH
}

\section{Bhawani Datt Joshi}

Journal of Institute of Science and Technology

Volume 22, Issue 1, July 2017

ISSN: 2469-9062 (print), 2467-9240 (e)

\section{Editors:}

Prof. Dr. Kumar Sapkota

Prof. Dr. Armila Rajbhandari

Assoc. Prof. Dr. Gopi Chandra Kaphle

JIST, 22 (1): 51-60 (2017)

Published by:

Institute of Science and Technology

Tribhuvan University

Kirtipur, Kathmandu, Nepal

Published by

Institute of Science and Technology

Tribhuvan University

Kintipur, Kathmanda, Nepal 


\title{
STRUCTURAL, ELECTRONIC AND VIBRATIONAL STUDY OF 4, 6-DICHLORO-5-METHYLPYRIMIDINE: A DFT APPROACH
}

\author{
Bhawani Datt Joshi \\ Department of Physics, Tribhuvan University, Siddhanath Sc. Campus, Mahendranagar, Nepal \\ Corresponding E-mail: pbdjoshi@gmail.com
}

\begin{abstract}
Molecular structure, molecular electrostatic potential (MEP) and theoretical vibrational spectra of 4, 6dichloro-5-methylpyrimidine (DMP) molecule have been presented in this paper. The vibrational spectra were calculated for monomer, dimer and unit cell DMP molecule using density function theory (DFT) and ab initio Hartree-Fock (HF) (for monomer) method employing 6-311++G (d, p) basis set using Gaussian 09 program. The frequencies obtained by DFT have smaller values than obtained from HF due to the inclusion of electron correlation in the previous one. Electronic absorption calculations are performed both in the gas and solvent phase using TD-DFT (including IEF-PCM model) to understand the stability, charge transfer and frontier molecular orbital energy gap. Large value of energy gap leads to the stability of molecule. Overlapping between calculated and the experimental structure show that the optimized geometry reproduced exactly similar structure as by the experiment.
\end{abstract}

Keywords: DMP, DFT, Vibrational spectra, MEP, IEF-PCM model.

\section{INTRODUCTION}

Nitrogen containing molecules have their wide medicinal applications. Pyrimidine derivatives containing nitrogen atoms are known for their pharmacological applications. They are used as pesticides, pharmaceutical agents (Condon et al., 1993; Maeno et al., 1990), antiviral agents (Alam et al., 2010), herbicides (Selby et al., 2002), antioxidant and for applications of organoselenide compounds (Khidre et al., 2013).The aim of present study is to investigate the vibrational frequencies of with potential energy distribution 4, 6-dichloro-5methylpyrimidine (DMP) together with the structural parameters. X-ray diffraction method is one of the most frequently applied techniques for structural characterization of pharmaceutical compounds which is sensible to the long-range order molecules. Nowadays, there has been increasing attention for the application of vibrational spectroscopy (Raman and infrared) for non-destructive characterization of substance having short-range molecular structure (Srivastava et al., 2013). The quantum mechanical methods are strongly supporting theoretical tools. Vibrational spectroscopy is a valuable method for studying the dynamical behavior and to gain insight into the electronic structures of macromolecules at microscopic level (Srivastava et al., 2013; Mishra et al., 2014). They have been widely used to study the energetic, thermal and dynamical behavior from vibrational dynamics of large number of molecules/ or biomolecules.

The crystalline structure of DMP was recently elucidated by Medjani et al. (2015). It crystallizes in a monoclinic system belonging to the $P 2_{1} / n$ space group with the crystal parameters: $\mathrm{a}=7.463$ (5), $b=7.827$ (5), $c=11.790$ (5) $\AA$ and $\beta=93.233$ $(5)^{\circ}$. The crystalline packing is governed by strong intermolecular hydrogen bonds involving both carbon (doner) and nitrogen (as acceptor) and forming inversion dimers. The crystal structure of DMP molecule is shown in figure 1 (a).

We have presented the vibrational modes of DMP for its monomer, dimer and the unit cell level using density functional theory (DFT) together with $a b$ initio Hartree Fock (HF) theory. Further, MEP and electronic absorption in gas as well as in the solvent phase together with HOMO-LUMO analysis has been included.

\section{MATERIALS AND METHOD}

\section{Computational details}

The hybrid density functional theory (DFT) (Hohenberg \& Kohn, 1964) calculations were 
mainly carried out in the frame-work of the Becke-Lee-Yang-Parr (B3LYP) functional, in which the exchange functional is a local spin density exchange with Becke gradient correction (Casida \& Chong, 1995) and the correlation functional is that of Lee, Yang and Parr with both local and non-local terms (Casida et al., 1998; Lee et al., 1988). Molecular geometry, vibrational frequencies and energies of optimized structures of the DMP were calculated employing 6-311++G (d, p) basis set (Becke, 1993; Parr \& Yang, 1989) using Gaussian 09 (Frisch et al., 2009) program package. The vibrational assignments of the normal modes were made on the basis of the band profile, intensity and PED, calculated along the internal coordinates employing localized symmetry using GAR2PED program (Martin \& Aslenov, 1995). For the molecule, isoelectronic molecular electrostatic potential surfaces (MEP) were calculated and plotted by the Gauss View program (Frisch et al. 2000) using DFT B3LYP/6-311++G (d, p) basis set.

\section{RESULTS AND DISCUSSION}

\section{Geometry optimization}

Taking the standard geometric parameters (Medjani et al., 2015), initial geometry was minimized without any constraints to the potential energy surface. These optimized parameters were used for vibrational frequency calculation to characterize all stationary points as minima. The ground state optimized structure of the molecule is as shown in the figure 1 (b). The optimized structure reproduced is remarkably similar to the experimental one. The calculated parameters (bond length, bond angle and the dihedral angles) are similar to the experimental values. Both the optimized and experimental molecular conformations were compared by superimposing them using a least-square algorithm that minimizes the distance between the corresponding non-hydrogen atoms, as shown in figure 1 (c). For clarity, all the hydrogen atoms were removed. The agreement between the optimized and the experimentally observed structure was excellent showing that optimized structure reproduces the experimentally observed conformation.

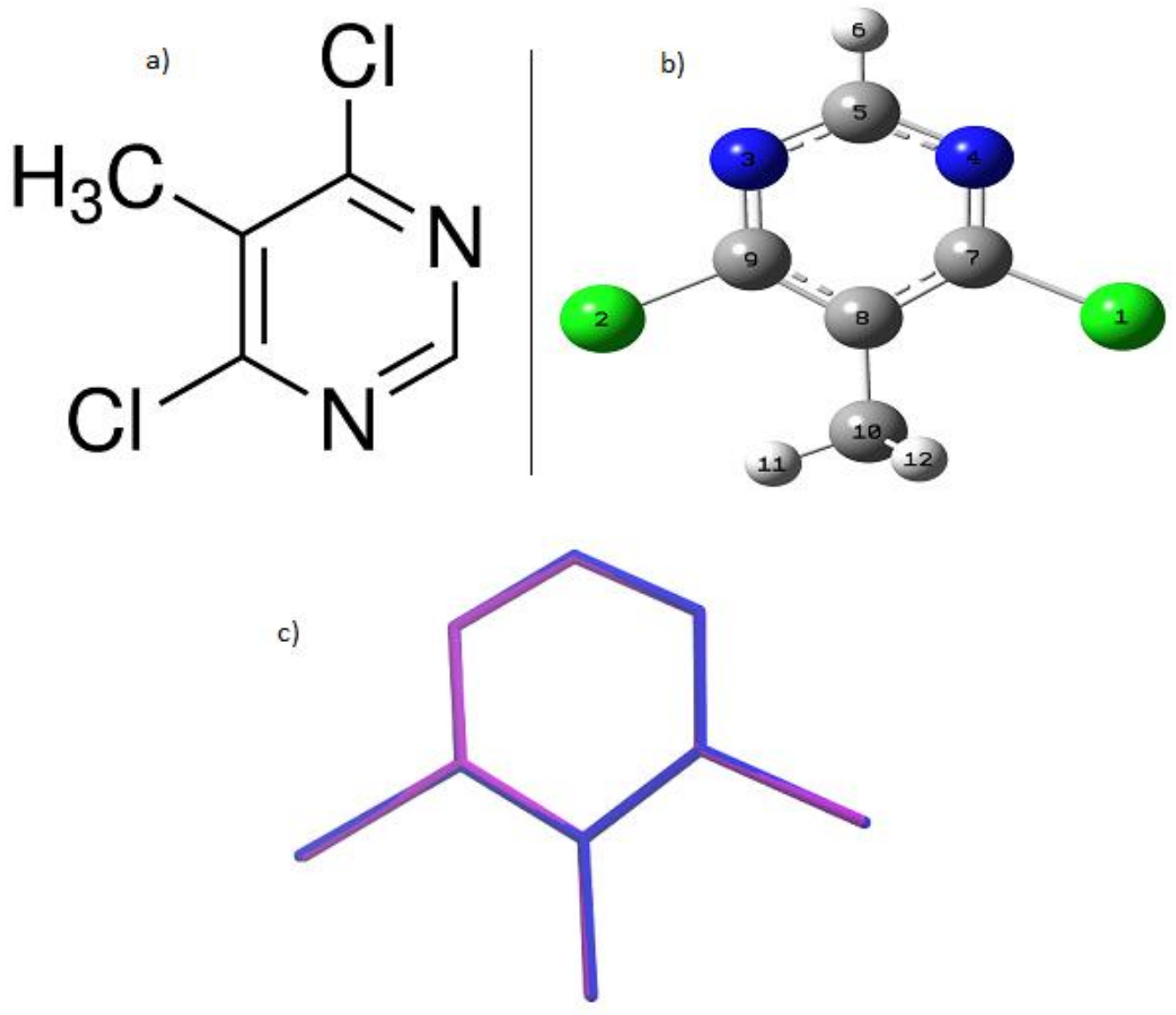

Fig. 1. (a) Crystal structure of DMP, (b) Optimized structure of DMP, and (c) Overlapping between the experimental (purple) and optimized (blue) structures. 
The relative minimum energies of the molecule calculated by employing ab initio $\mathrm{HF}$ functions and B3LYP functional are -1219.64827061 and 1222.97130444 Hartree, respectively. The enthalpy difference between these two theories is
$4.07194 \mathrm{kcal} / \mathrm{mol}$. Also, a comparison between experimental and optimized hydrogen bond parameters is as shown in the Table 1. The optimized structure of dimer and unit cell are as shown in the figure $2(\mathrm{a} \& \mathrm{~b})$.

Table 1. Comparison between the experimental and optimized H-bond parameters.

\begin{tabular}{llllll}
\hline & $\mathrm{D}-\mathrm{H}----\mathrm{A}$ & $\mathrm{D}-\mathrm{A}(\AA)$ & $\mathrm{H} \ldots . . \mathrm{A}(\AA)$ & $\mathrm{D} \ldots \mathrm{A}(\AA)$ & $\mathrm{D}-\mathrm{H} \ldots \mathrm{A}\left({ }^{\circ}\right)$ \\
\hline Expt. & $\mathrm{C} 2-\mathrm{H} 2 . . \mathrm{N} 3^{\mathrm{i}}$ & 0.93 & 2.66 & $3.468(6)$ & 146 \\
Cal. & $\cdots$ & 1.0845 & 2.6097 & 3.38428 & 137 \\
\hline
\end{tabular}

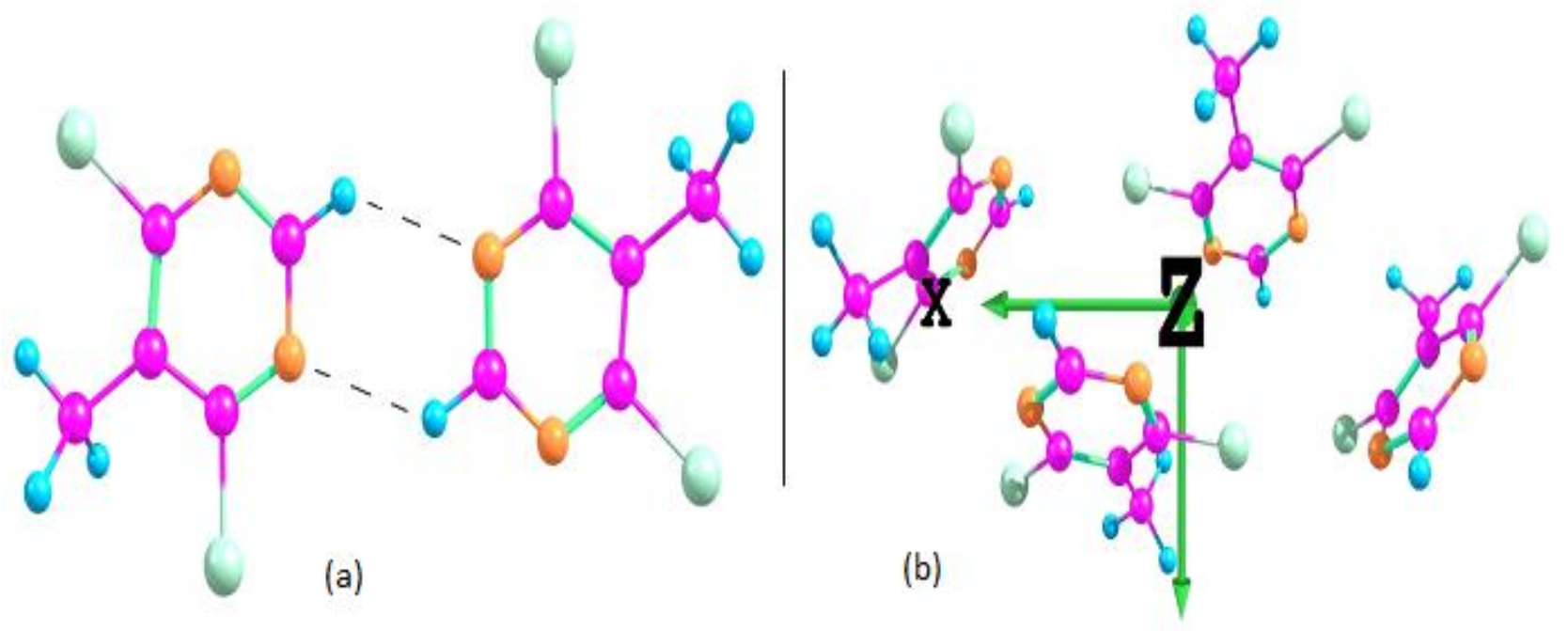

Fig. 2. Optimize structures; (a) dimer and (b) unit cell of DMP molecule.

\section{Molecular electrostatic potential (MEP)}

The molecular electrostatic potential (MEP) in a molecule at a point $r(x, y, z)$ is the force on unitary positive test charge at that point due to its whole electrical charge and is given by:

$$
V(r)=\sum_{A} \frac{Z_{A}}{\left|\vec{R}_{A}-\vec{r}\right|}-\int \frac{\rho\left(\overrightarrow{r^{\prime}}\right) d r}{\left|\overrightarrow{r^{\prime}}-\vec{r}\right|}
$$

where $Z_{A}$ is the charge on nucleus A located at $R_{A}$ and $\rho\left(r^{\prime}\right)$ is the electron density. The first term is due to the nucleus and the second due to electron cloud.

The MEP provides a visual method to understand the relative polarization of molecule (Srivastava et al., 2013). Such surfaces depict the size, shape, charge density and site of chemical reactivity of the molecules. In the surface generated, negative electrostatic potential (shades of red color) corresponds to an attraction of the proton by the concentrated electron density in the molecules (from lone pairs, pi-bonds, etc.) and positive electrostatic potential (shades of blue color) corresponds to repulsion of the proton by the atomic nuclei in the regions where low electron density exists and the nuclear charge is incompletely shielded. The largely white or lighter color shades on the surface indicate that the molecule is mostly non-polar. The potential increases in the order red < orange < yellow < green < blue.

Molecular electrostatic potential surface (MEP) of DMP molecule mapped with the output obtained by B3LYP/6-311++G $(\mathrm{d}, \mathrm{p})$ is as shown in figure 3. From the figure it is clear that the most negative regions (red regions) are localized over the nitrogen atoms as the sites for nucleophilic reactivity. Similarly, the most positive region (blue region) is localized over the hydrogen atoms of methyl group which is expected to be electrophilic regions. 


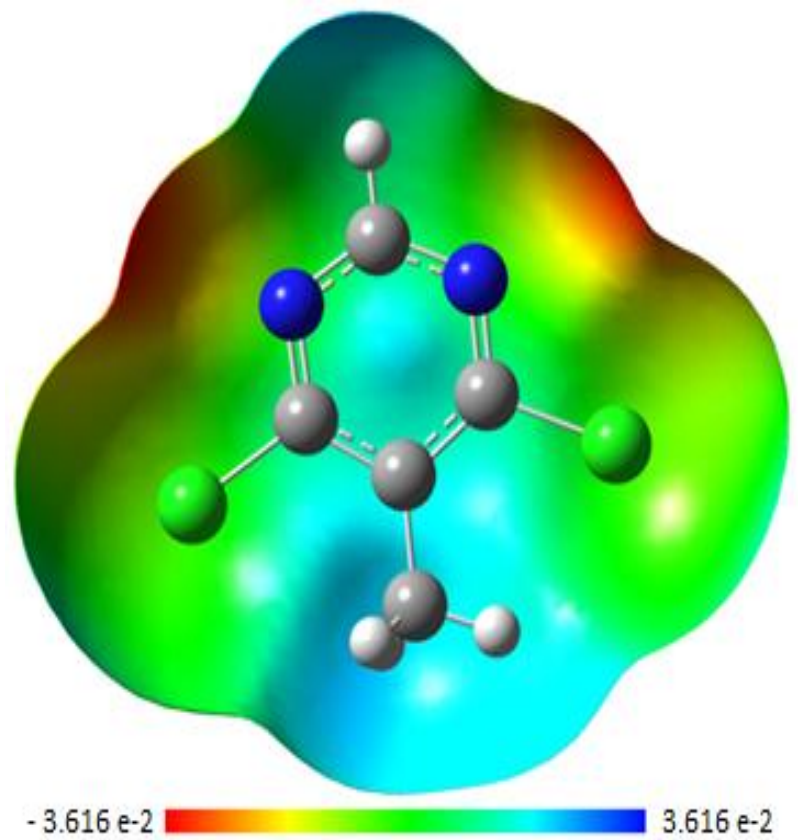

Fig. 3. Molecular electrostatic potential mapped.

\section{Electronic absorbance and HOMO-LUMO band gap}

The frontier molecular orbitals characterized by HOMO (highest occupied molecular orbital) and LUMO (lowest unoccupied molecular orbital) are the most significant orbitals in a molecule. These orbitals play vital role in predicting electric and optical properties. The energy of the HOMO is directly related to the ionization potential and the energy of the LUMO is directly related to the electron affinity. Higher gap energy $(\Delta \mathrm{E})$ indicates more stability of molecule and vice versa. Usually, a molecule with small frontier gap is more optically polarizable, kinetically less stable, has high conductivity and high reactivity in chemical reactions (Lewis et al., 1994). The calculated electronic absorption spectra in both the gas and solvent phase (DMSO; Dimethyl sulphoxide) using time dependent density functional theory (TD-DFT) employing 6-31G $(\mathrm{d}, \mathrm{p})$ basis set is shown below in the figure 4 .

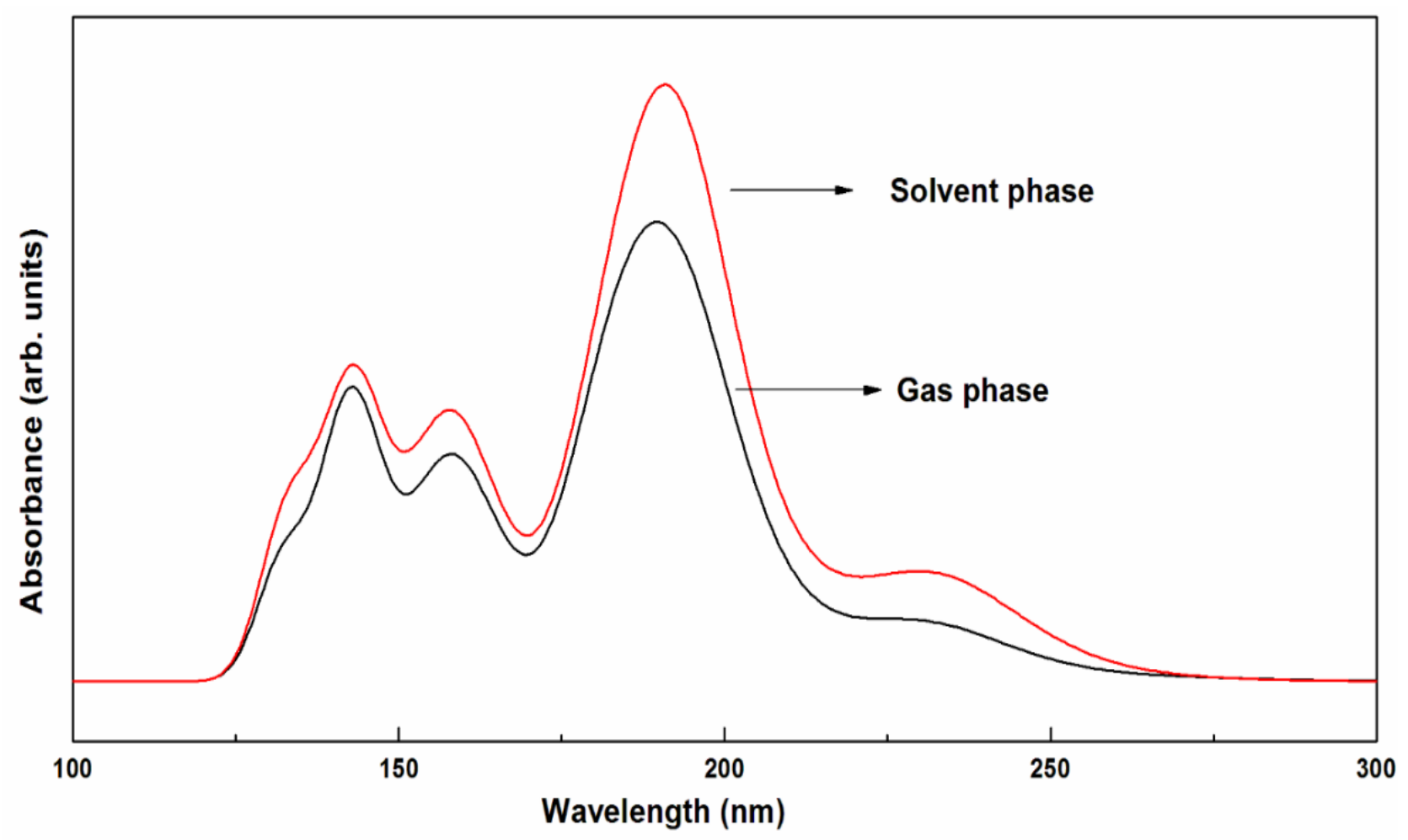

Fig. 4. UV-Vis absorption spectrum of the title molecule.

The calculated frontier orbital energies, absorption wavelengths $\left(\lambda_{\max }\right)$, oscillator strengths (f), excitation energies (E), and dipole moments $(\mu)$ for gas as well as the solvent phase are illustrated in table 2. The electronic absorption corresponds to the transition of an electron from the HOMO (referred as ground state) to the LUMO (as first excited state). 
Table 2. Electronic transitions, absorption wavelength $\lambda_{\max }(\mathrm{nm})$, excitation energy $(\mathrm{eV})$, oscillator strengths (f), frontier orbital energies (eV) and dipole moment (Debye).

\begin{tabular}{|c|c|c|c|c|c|c|c|c|}
\hline \multirow{2}{*}{$\begin{array}{l}\text { Excited } \\
\text { State }\end{array}$} & \multicolumn{4}{|c|}{ Gas phase } & \multicolumn{4}{|c|}{ Solvent (DMSO) phase } \\
\hline & $\begin{array}{l}\lambda_{\max } \\
(\mathrm{nm})\end{array}$ & Transitions & $\mathrm{E}(\mathrm{ev})$ & $\begin{array}{l}\text { Oscillator } \\
\text { strength (f) }\end{array}$ & $\lambda_{\max }(\mathrm{nm})$ & Transitions & $\mathrm{E}(\mathrm{ev})$ & $\begin{array}{l}\text { Oscillator } \\
\text { strength (f) }\end{array}$ \\
\hline 1 & 263.49 & $\mathrm{H} \rightarrow \mathrm{L}$ & 4.7055 & 0.0044 & 258.15 & $\mathrm{H}-1 \rightarrow \mathrm{L}$ & 4.8028 & 0.0050 \\
\hline 2 & 231.08 & $\mathrm{H}-1 \rightarrow \mathrm{L}$ & 5.3654 & 0.0559 & 232.63 & $\mathrm{H} \rightarrow \mathrm{L}$ & 5.3297 & 0.1018 \\
\hline 3 & 209.04 & $\mathrm{H}-1 \rightarrow \mathrm{L}+1$ & 5.9311 & 0.0380 & 209.86 & $\mathrm{H} \rightarrow \mathrm{L}+1$ & 5.9079 & 0.0636 \\
\hline 4 & 199.72 & $\mathrm{H}-3 \rightarrow \mathrm{L}$ & 6.2080 & 0.0049 & 196.48 & $\mathrm{H}-4 \rightarrow \mathrm{L}+1$ & 6.3103 & 0.0049 \\
\hline 5 & 193.87 & $\mathrm{H}-2 \rightarrow \mathrm{L}$ & 6.3951 & 0.1464 & 193.89 & $\mathrm{H}-2 \rightarrow \mathrm{L}$ & 6.3946 & 0.2070 \\
\hline 6 & 192.78 & $\mathrm{H}-2 \rightarrow \mathrm{L}+1$ & 6.4315 & 0.1945 & 191.98 & $\mathrm{H}-2 \rightarrow \mathrm{L}+1$ & 6.4583 & 0.2981 \\
\hline 7 & 182.11 & $\mathrm{H} \rightarrow \mathrm{L}+2$ & 6.8082 & 0.2394 & 181.19 & $\mathrm{H}-1 \rightarrow \mathrm{L}+2$ & 6.8428 & 0.2251 \\
\hline 8 & 158.09 & $\mathrm{H}-3 \rightarrow \mathrm{L}+2$ & 7.8424 & 0.0450 & 157.27 & $\mathrm{H}-3 \rightarrow \mathrm{L}+2$ & 7.8837 & 0.0520 \\
\hline 9 & 156.35 & $\mathrm{H} \rightarrow \mathrm{L}+3$ & 7.9299 & 0.1205 & 155.97 & $\mathrm{H}-1 \rightarrow \mathrm{L}+3$ & 7.9494 & 0.1373 \\
\hline 10 & 143.38 & $\mathrm{H}-7 \rightarrow \mathrm{L}+1$ & 8.6470 & 0.1184 & 143.70 & $\mathrm{H}-7 \rightarrow \mathrm{L}$ & 8.6282 & 0.1944 \\
\hline \multirow[t]{2}{*}{11} & 142.67 & $\mathrm{H}-7 \rightarrow \mathrm{L}$ & 8.6903 & 0.1654 & 142.79 & $\mathrm{H}-7 \rightarrow \mathrm{L}+1$ & 8.6832 & 0.0911 \\
\hline & \multicolumn{2}{|c|}{$\mathrm{E}_{\text {номо }}(\mathrm{eV})$} & \multicolumn{2}{|c|}{$\mathrm{E}_{\text {LUMO }}(\mathrm{eV})$} & $\Delta \mathrm{E}(\mathrm{eV})$ & \multicolumn{2}{|c|}{$\mu(D)$} & \\
\hline Gas & \multicolumn{2}{|c|}{-6.687113} & \multicolumn{2}{|c|}{-1.607280} & 5.079833 & \multicolumn{2}{|c|}{1.4808} & \\
\hline Solvent & \multicolumn{2}{|c|}{-7.655984} & \multicolumn{2}{|c|}{-1.580368} & 5.979472 & \multicolumn{2}{|c|}{1.9121} & \\
\hline
\end{tabular}

HOMO $=41$, LUMO $=42$

The first allowed transition $(\mathrm{H} \rightarrow \mathrm{L})$ in gas phase was calculated at $263.49 \mathrm{~nm}$ with oscillator strength 0.0044 and in solvent phase it was at $258.15 \mathrm{~nm}(\mathrm{H}-1 \rightarrow \mathrm{L})$ with oscillator strength 0.050 . The other main transitions in the gas phase were calculated at $231.08 \mathrm{~nm}(\mathrm{H}-1 \rightarrow \mathrm{L}), 192.78$ $\mathrm{nm} \quad(\mathrm{H}-2 \rightarrow \mathrm{L}+1), \quad 182.11 \quad(\mathrm{H} \rightarrow \mathrm{L}+2), \quad 156.35$ $(\mathrm{H} \rightarrow \mathrm{L}+3)$ and $142.67 \mathrm{~nm} \quad(\mathrm{H}-7 \rightarrow \mathrm{L})$ with oscillator strengths $0.0559,0.1945,2394,0.1205$ and 0.1654 , respectively. Similarly, in the solvent phase the main transitions were at 232.63 $(\mathrm{H} \rightarrow \mathrm{L}), 191.98(\mathrm{H}-2 \rightarrow \mathrm{L}+1), 181.19(\mathrm{H}-1 \rightarrow \mathrm{L}+2)$, $155.97(\mathrm{H}-1 \rightarrow \mathrm{L}+3)$ and $143.70 \mathrm{~nm}(\mathrm{H}-7 \rightarrow \mathrm{L})$ with the oscillator strengths $0.1018,0.2981$, $0.2251,0.1373$ and 0.1944 , respectively. DMSO being a polar aprotic solvent, increases the polarity of the molecule as such the calculated dipole moment in the solvent phase (1.9121) is higher than in the gas phase (1.4808). Similarly, the energy difference $\left(\Delta \mathrm{E}=\mathrm{E}_{\mathrm{LumO}}-\mathrm{E}_{\text {Hомо }}\right)$ between the two molecular orbitals was 5.079833 and $5.979472 \mathrm{eV}$, respectively in the solvent and gas phases.

Figure 5 shows HOMO-LUMO plot for the different molecular orbitals taking part in the charge accumulation process in the gaseous phase. The red regions indicate to the positive charge and blue regions to the negative charge accumulating parts of the molecule. In HOMO, charge is accumulated from nitrogen and chlorine molecules together with the charge from ring, while in LUMO the charge accumulation occurred at the ring elements (nitrogen and carbon). In HOMO-1 and HOMO-2 the charge is mainly accumulated from the ring and chlorine atom while in case of LUMO+1 almost the charge is accumulated at the ring elements. In HOMO-7 the charge accumulation is dominated by the lone-pair elements. In this molecule main transition types are $\pi \rightarrow \pi^{*}$ in the ring and and $n \rightarrow \pi^{*}$ (in the lone-pair elements). 


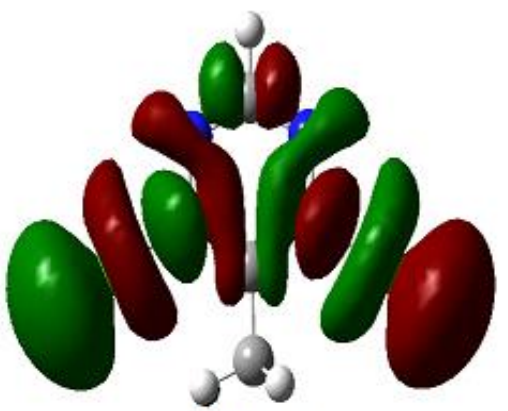

LUMO+3

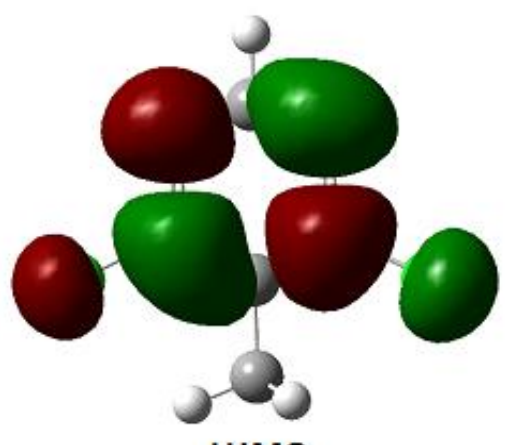

LUMO

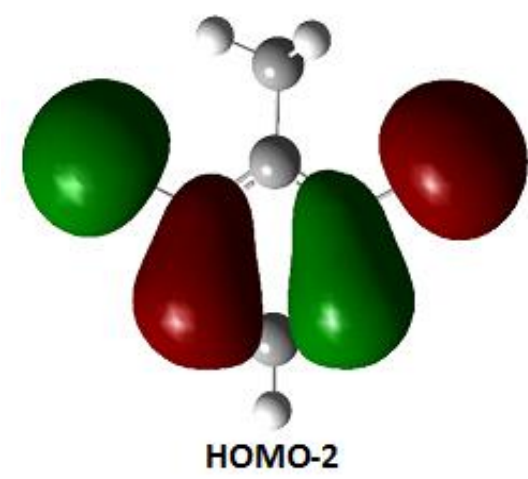

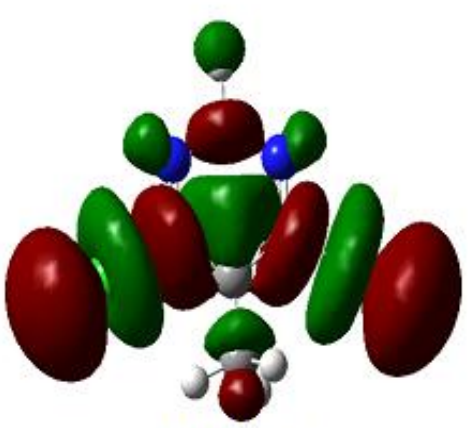

LUMO+2
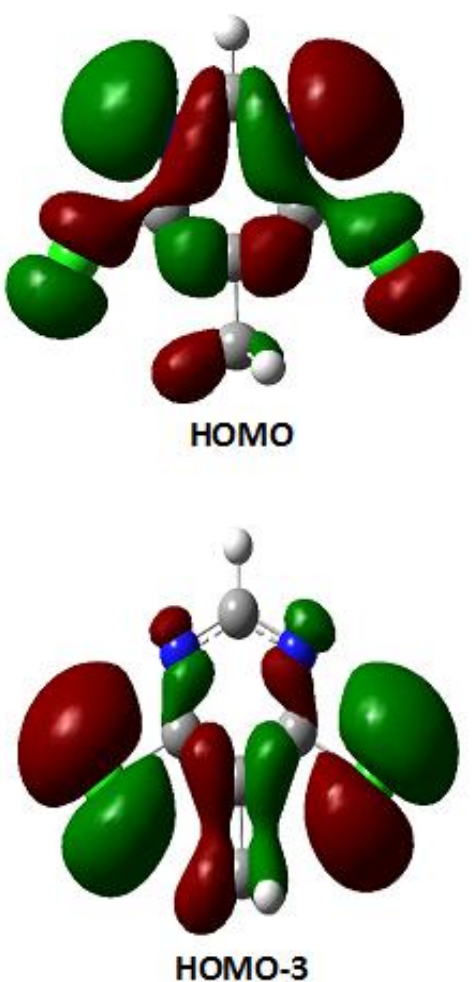
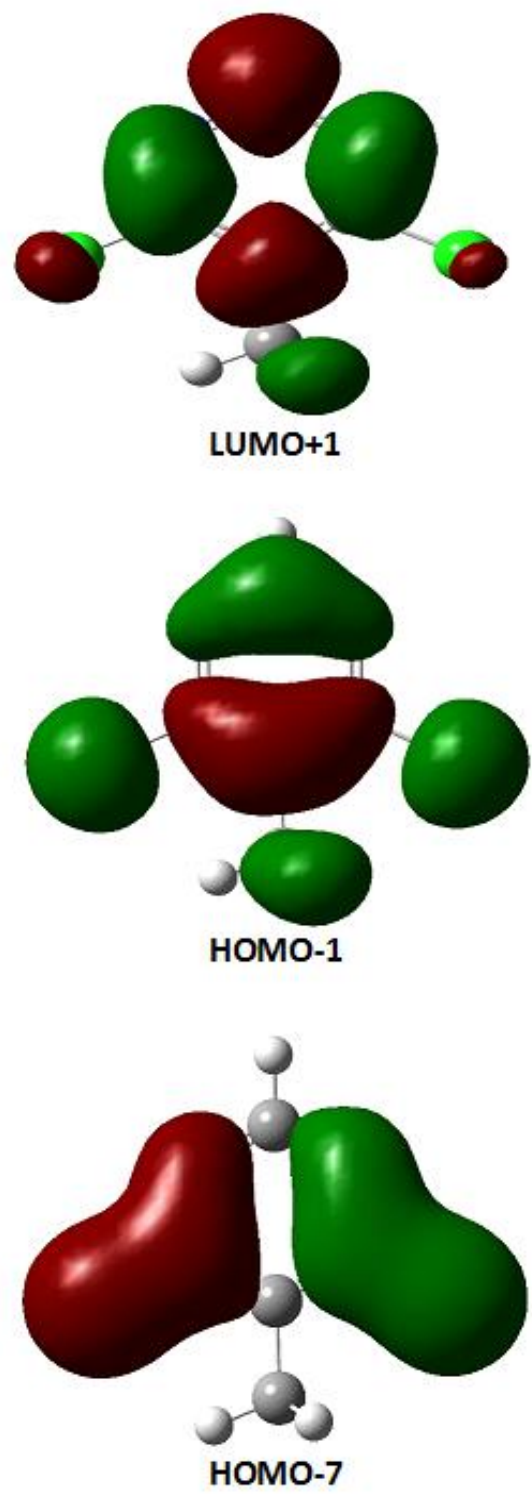

Fig. 5. Plots of HOMOs and LUMOs of DPN molecule showing the charge accumulation.

\section{Vibrational frequencies}

DMP molecule has 13 atoms, hence it gives 33 $(3 \mathrm{~N}-6 ; \mathrm{N}$ is the number atoms) modes of vibrations. All the frequencies / wavenumbers are both Raman and IR active. The calculated frequencies (for monomer, dimer and unit cell) have been scaled by the wavenumber linear scaling (WLS) of Yoshida et al. 2002 using the expression: $v_{\mathrm{obs}}=\left(1.0087-0.0000163 \mathrm{v}_{\text {cal }}\right) \mathrm{v}_{\text {cal }}$. The calculated frequencies of DMP molecule for its monomer, dimer and unit cell level are listed in the Table 3. The Raman and IR spectra are shown in the figure 6 and 7, respectively. Further, a brief assignment of these frequencies according as the numbering system as shown in figure 6 is given below:

\section{Methyl vibration}

$\mathrm{CH}_{3}$ group has several modes associated with it, such as symmetric and asymmetric stretches, bends, rocks, and torsional modes. In this study, the asymmetric stretching was calculated at 3020 and $2962 \mathrm{~cm}^{-1}$ in the monomer. This vibration has same values in the dimer while there was small difference in unit cell. Symmetric vibration related to this group was at $2919 \mathrm{~cm}^{-1}$, which was strong in the Raman and weak in the IR band. The deformation vibrations of $\mathrm{CH}_{3}$ were calculated at 1465 and $1462 \mathrm{~cm}^{-1}$. 


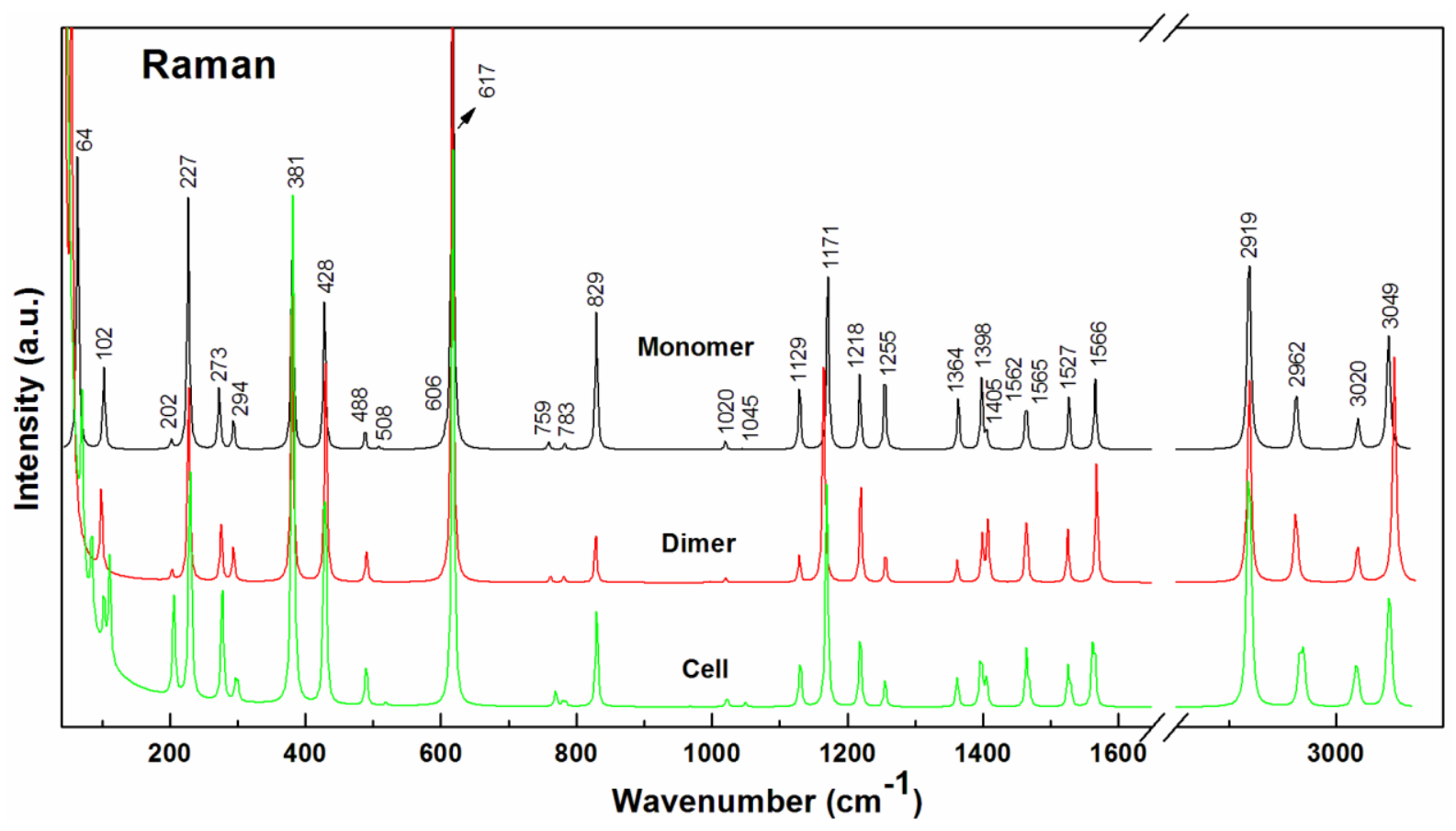

Fig. 6. Calculated Raman spectra.

\section{Pyrimidine ring vibration}

There are two chlorides, one methine and a methyl group as functional groups attached to the pyrimidine ring. C-H stretching vibration was calculated at $3049 / 3211 \mathrm{~cm}^{-1}$ in the scaled DFT/HF, respectively. The in-plane deformation vibration for monomer was at $1405 \mathrm{~cm}^{-1}$ in DFT and at $1529 \mathrm{~cm}^{-1}$ in the HF method. The two values of this mode in the dimer are 1409 and $1407 \mathrm{~cm}^{-1}$. Similarly, the four values of the in-plane deformation in the cell are 1407, 1406, 1405 and
$1405 \mathrm{~cm}^{-1}$, respectively. C-H out-of-plane vibration for monomer was at $927 \mathrm{~cm}-1$ in DFT.

This mode was calculated respectively at 997/ 994 $\mathrm{cm}^{-1}$ in the dimer and at 969,969,968 and $968 \mathrm{~cm}^{-1}$ in the cell.

C-Cl stretching vibration was calculated at 428 / $381 \mathrm{~cm}^{-1}$ in DFT and $471 / 416 \mathrm{~cm}^{-1}$ in the HF. This vibration has been obtained in the range 430-380 $\mathrm{cm}^{-1}$ in case of both the dimer and unit cell. The inplane vibration of $\mathrm{C}-\mathrm{Cl}$ mode was at $227 \mathrm{~cm}^{-1}$ in DFT method.

Table 3. Calculated wave numbers (in $\mathrm{cm}^{-1}$ ) of DMP for its monomer, dimer and unit cell.

\begin{tabular}{|c|c|c|c|c|c|}
\hline \multirow{3}{*}{$\begin{array}{l}\text { Unscaled } \\
\text { DFT }\end{array}$} & \multicolumn{4}{|c|}{ Scaled wave numbers } & \multirow[t]{3}{*}{$\mathrm{PED}^{\mathrm{a}}$ distribution (\%) } \\
\hline & \multicolumn{2}{|c|}{ Monomer } & \multirow{2}{*}{$\begin{array}{l}\text { Dimer } \\
\text { DFT }\end{array}$} & Cell & \\
\hline & $\mathrm{HF}$ & DFT & & & \\
\hline 3187 & 3211 & 3049 & 3055,3053 & $3051,3051,3049,3049$ & $v(\mathrm{CH})(99)$ \\
\hline 3155 & 3161 & 3020 & 3020,3020 & $3020,3020,3018,3018$ & $v_{a}\left(\mathrm{CH}_{3}\right)(99)$ \\
\hline 3091 & 3101 & 2962 & 2962,2962 & $2969,2969,2966,2966$ & $\mathrm{v}_{\mathrm{a}}\left(\mathrm{CH}_{3}\right)(100)$ \\
\hline 3043 & 3053 & 2919 & 2918,2918 & $2920,2920,2918,2918$ & $v_{s}\left(\mathrm{CH}_{3}\right)(100)$ \\
\hline 1593 & 1730 & 1566 & 1568,1564 & $1565,1565,1563,1531$ & $\begin{array}{l}v(\mathrm{C}=\mathrm{N})(46)+v(\mathrm{CC})(24)+\mathrm{R}\left[\delta_{\mathrm{a}^{\prime}}\right](8)+v(\mathrm{CN})(8)+ \\
v(\mathrm{C} 8 \mathrm{C} 10)(5)\end{array}$ \\
\hline 1553 & 1707 & 1527 & 1528,1525 & $1530,1530,1527,1525$ & $v(\mathrm{CN})(38)+\delta_{\text {in }}(\mathrm{CH})(16)+v(\mathrm{CC})(26)+\mathrm{R}\left[\delta_{\mathrm{a}}\right](6)$ \\
\hline 1488 & 1585 & 1465 & 1465,1465 & $1469,1469,1465,1465$ & {$\left[\delta_{\mathrm{a}}(81)+\rho^{\prime}(8)\right](\mathrm{CH} 3)$} \\
\hline
\end{tabular}




\begin{tabular}{|c|c|c|c|c|c|}
\hline 1485 & 1583 & 1462 & 1464,1463 & $1464,1464,1463,1463$ & {$\left[\delta_{\mathrm{a}} \cdot(69)+\rho(8)\right]\left(\mathrm{CH}_{3}\right)+\delta_{\text {in }}(\mathrm{CH})(10)$} \\
\hline 1426 & 1529 & 1405 & 1409,1407 & $1407,1406,1405,1405$ & $\delta_{\text {in }}(\mathrm{CH})(34)+\delta_{\mathrm{s}}\left(\mathrm{CH}_{3}\right)(31)+\mathrm{v}(\mathrm{CC})(11)+\mathrm{v}(\mathrm{C}=\mathrm{N})(9)$ \\
\hline 1419 & 1523 & 1398 & 1400,1400 & $1399,1399,1396,1396$ & $\delta_{\mathrm{s}}\left(\mathrm{CH}_{3}\right)(67)+\delta_{\text {in }}(\mathrm{CH})(13)+\mathrm{v}(\mathrm{C} 8 \mathrm{C} 10)(5)$ \\
\hline 1383 & 1481 & 1364 & 1362,1361 & $1364,1364,1363,1361$ & $v(\mathrm{C} 8 \mathrm{C} 10)(21)+v(\mathrm{CC})(30)+v(\mathrm{CN})(29)+v(\mathrm{C}=\mathrm{N})(9)$ \\
\hline 1270 & 1364 & 1255 & 1256,1248 & $1257,1256,1255,1254$ & $\begin{array}{l}v(\mathrm{CN})(42)+v(\mathrm{CC})(20)+\delta_{\text {in }}(\mathrm{C} 8 \mathrm{C} 10)(11)+\delta_{\text {in }}(\mathrm{CH})(8)+\rho \\
\left(\mathrm{CH}_{3}\right)(7)\end{array}$ \\
\hline 1232 & 1273 & 1218 & 1233,1230 & $1220,1219,1218,1217$ & $v(\mathrm{C}=\mathrm{N})(56)+v(\mathrm{CC})(17)+v(\mathrm{CN})(16)+\delta_{\text {in }}(\mathrm{CH})(6)$ \\
\hline 1183 & 1231 & 1171 & 1169,1165 & $1171,1170,1170,1169$ & $\begin{array}{l}v(\mathrm{CN})(45)+v(\mathrm{C}=\mathrm{N})(20)+\mathrm{R}\left[\delta_{\text {trig }}\right](12)+v(\mathrm{C} 8 \mathrm{C} 10)(10)+ \\
v(\mathrm{C}=\mathrm{N})(6)\end{array}$ \\
\hline 1140 & 1169 & 1129 & 1129,1128 & $1132,1131,1129,1129$ & $\mathrm{R}\left[\delta_{\text {trig }}\right](52)+v(\mathrm{C} 8 \mathrm{C} 10)(16)+\mathrm{v}(\mathrm{CN})(18)$ \\
\hline 1054 & 1145 & 1045 & 1046,1046 & $1049,1049,1047,1047$ & {$\left[\rho^{\prime}(78)+\delta_{\mathrm{a}}(6)\right]\left(\mathrm{CH}_{3}\right)+\delta_{\text {out }}(\mathrm{C} 8 \mathrm{C} 10)(7)$} \\
\hline 1028 & 1099 & 1020 & 1020,1020 & $1024,1023,1022,1021$ & $\rho\left(\mathrm{CH}_{3}\right)(63)+v(\mathrm{CC})((13)+v(\mathrm{CN})(9)$ \\
\hline 979 & 1085 & 972 & 997, 994, & $969,969,968,968$ & $\delta_{\text {out }}(\mathrm{CH})(91)+\mathrm{R}[$ puck $](5)$ \\
\hline 833 & 903 & 829 & 828,828 & $831,831,830,830$ & $\begin{array}{l}\mathrm{R}\left[\delta_{\mathrm{a}^{\prime}}(34)+\delta_{\text {trig }}(19)\right]+v(\mathrm{C} 8 \mathrm{C} 10)(17)+\mathrm{v}(\mathrm{CCl})(13)+ \\
\mathrm{v}(\mathrm{CC})(9)\end{array}$ \\
\hline 786 & 853 & 783 & 783,781 & $785,785,781,780$ & $\mathrm{R}\left[\delta_{\mathrm{a}}\right](41)+v(\mathrm{CCl})(40)+v(\mathrm{CC})(10)$ \\
\hline 762 & 844 & 759 & 762,762 & $770,770,769,768$ & $\mathrm{R}[$ puck $](62)+\delta_{\text {out }}(\mathrm{CCl})(27)+\delta_{\text {out }}(\mathrm{C} 8 \mathrm{C} 10)(8)$ \\
\hline 618 & 677 & 617 & 617,617 & $618,618,618,618$ & $\begin{array}{l}\mathrm{R}\left[\delta_{\mathrm{a}^{\mathrm{a}}}\right](34)+\mathrm{v}(\mathrm{C} 8 \mathrm{C} 10)(25)+\mathrm{v}(\mathrm{CCl})(19)+\mathrm{v}(\mathrm{CC})(9)+ \\
\mathrm{v}(\mathrm{CN})(7)\end{array}$ \\
\hline 607 & 660 & 606 & 605,604 & $611,610,609,609$ & $\mathrm{R}\left[\tau_{\mathrm{a}}\right](75)+\delta_{\text {out }}(\mathrm{CCl})(35)$ \\
\hline 508 & 559 & 508 & 516,509 & $519,519,518,518$ & $\mathrm{R}\left[\tau_{\mathrm{a}^{\mathrm{a}}}\right](44)+\delta_{\text {in }}(\mathrm{C} 8 \mathrm{C} 10)(32)+\delta_{\text {out }}(\mathrm{CCl})(19)$ \\
\hline 488 & 530 & 488 & 490,490 & $491,490,489,489$ & $\begin{array}{l}\delta_{\text {in }}(\mathrm{C} 8 \mathrm{C} 10)(35)+\delta_{\text {in }}(\mathrm{CCl})(32)+\mathrm{R}\left[\delta_{\mathrm{a}}\right](15)+v(\mathrm{CN})(7)+ \\
\rho\left(\mathrm{CH}_{3}\right)(5)\end{array}$ \\
\hline 427 & 471 & 428 & 430,427 & $430,430,428,428$ & $v(\mathrm{CCl})(40)+v(\mathrm{CN})(30)+\mathrm{R}\left[\delta_{\mathrm{a}}\right](20)+\delta_{\text {in }}(\mathrm{C} 8 \mathrm{C} 10)(6)$ \\
\hline 380 & 416 & 381 & 380,380 & $382,382,380,380$ & $v(\mathrm{CCl})(31)+v(\mathrm{CN})(29)+\mathrm{R}\left[\delta_{\mathrm{a}^{\prime}}(21)+\delta_{\text {trig }}(8)\right]$ \\
\hline 293 & 317 & 294 & 294,294 & $300,300,297,297$ & $\delta_{\text {in }}(\mathrm{C} 8 \mathrm{C} 10)(47)+\delta_{\text {in }}(\mathrm{CCl})(42)+\mathrm{R}\left[\delta_{\mathrm{a}}\right](6)$ \\
\hline 271 & 299 & 273 & 375,374 & $278,277,277,277$ & $\delta_{\text {out }}(\mathrm{C} 8 \mathrm{C} 10)(55)+\delta_{\text {out }}(\mathrm{CCl})(38)$ \\
\hline 226 & 245 & 227 & 228,227 & $231,231,228,228$ & $\delta_{\text {in }}(\mathrm{CCl})(86)+\mathrm{v}(\mathrm{CC})(6)$ \\
\hline 201 & 230 & 202 & 203,203 & $207,207,206,205$ & $\mathrm{R}\left[\tau_{\mathrm{a}}\right](90)+\delta_{\text {out }}(\mathrm{CCl})(11)$ \\
\hline 102 & 120 & 102 & $\begin{array}{l}99,99 \\
55,45\end{array}$ & $\begin{array}{l}111,111,104,103 \\
85,84,70,69\end{array}$ & $\tau(\mathrm{C} 8 \mathrm{C} 10)(55)+\mathrm{R}\left[\tau_{\mathrm{a}^{\prime}}\right](26)$ \\
\hline 63 & 75 & 64 & $\begin{array}{l}31,31, \\
17,13,7\end{array}$ & $\begin{array}{l}41,39,31,29,29,28,28, \\
27,22,21,20,19,17, \\
16,14,9,9,5\end{array}$ & $\tau(\mathrm{C} 8 \mathrm{C} 10)(46)+\mathrm{R}\left[\tau_{\mathrm{a}^{\prime}}(32)+\operatorname{puck}(9)\right]$ \\
\hline
\end{tabular}

(Proposed assignments and potential energy distribution (PED) for vibrational normal modes. Types of vibration: $v$, stretching; $\delta$, deformation (bending), scissoring; oop, out-of-plane bending; $\omega$, wagging; $\gamma$, twisting; $\rho$, rocking; $\tau$, torsion; ${ }^{a}$ Potential energy distribution (contribution $\geq 5$ )).

C8-C10 stretching vibration was calculated at 1364 $\mathrm{cm}^{-1}$ in the scaled DFT and at $1481 \mathrm{~cm}^{-1}$ in $\mathrm{HF}$ method. The in-plane and out-of-plane vibrations of C8-C10 were at 294 and $273 \mathrm{~cm}^{-1}$, respectively. 


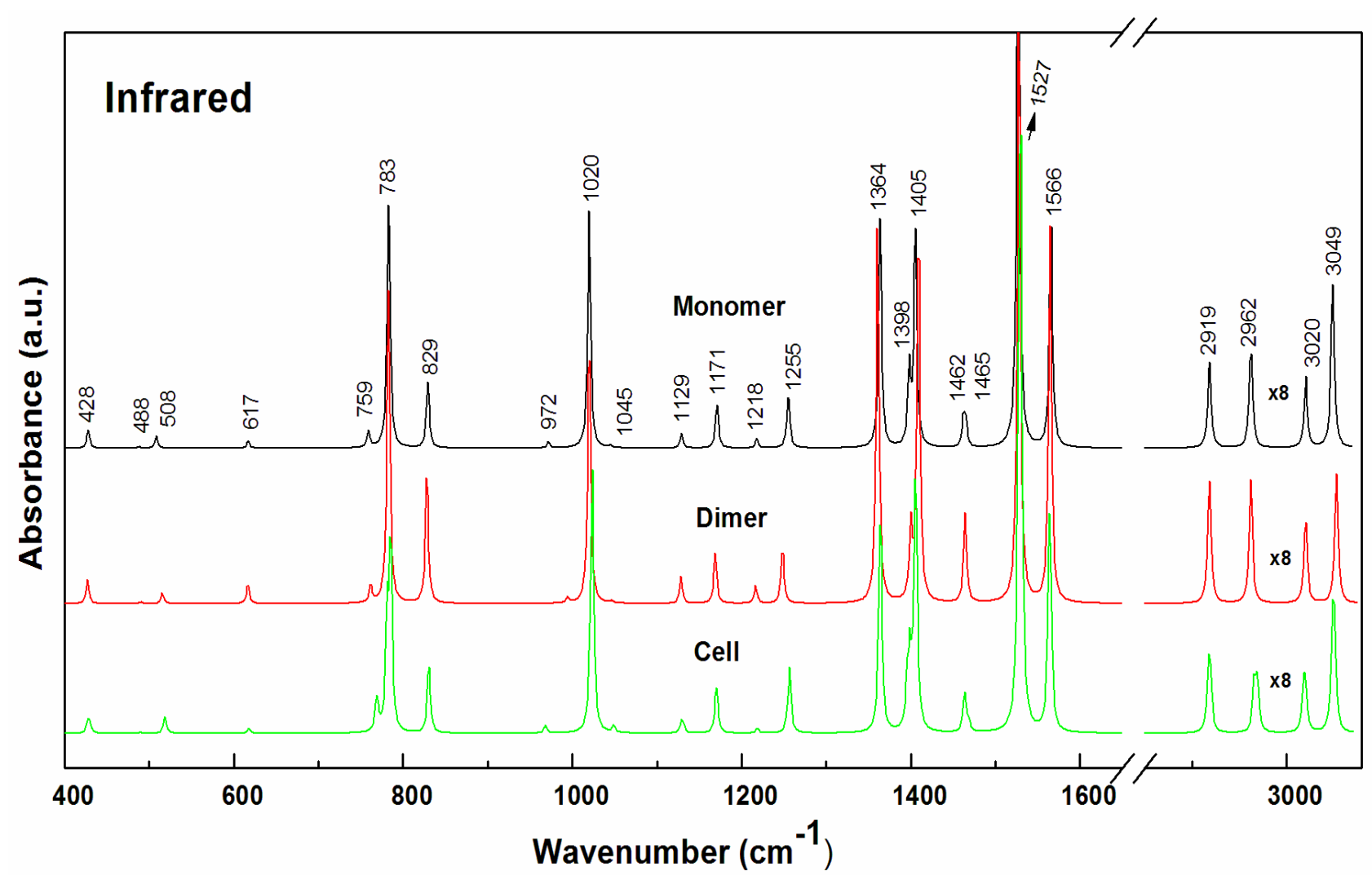

Fig. 7. Calculated infrared spectra.

\section{CONCLUSION}

The equilibrium geometries and harmonic vibrational wave numbers of all the 33 normal modes, the monomer, 72 normal modes of dimer and 150 normal modes of unit cell of DPN molecule were determined and analyzed both at DFT (B3LYP) theory employing the $6-311++\mathrm{G}(\mathrm{d}$, p) basis set. These spectra are in good agreement. These vibrational assignments along with the electronic transitions are important to understand the molecular structure of the title molecule. The Hbond length of $2.6093 \AA$ between the two molecules of dimer indicates that the molecular system is governed by strong H-bonding in its packing. The MEP plot shows that the regions near the nitrogen and chlorine atoms are most electronegative while the regions near the hydrogen atoms are most electro positive. The frontier energy gap is higher in the solvent phase than in the gas phase. The HOMO-LUMO plot notices that the charge transfer takes place within the molecule.

\section{ACKNOWLEDEGEMENTS}

The Brazilian National Council for Scientific and Technological Development (CNPq) and TWAS, the academy of sciences for the developing world (CNPq-TWAS/Post-Doc fellowship (2014) are highly acknowledged.

\section{REFERENCES}

Alam, O.; Khan, S. A.; Siddiqui, N. and Ahsan, W. (2010). Medicinal Chemistry Research, 19 (9): 1245-1258.

Becke, A. D. (1993). Density-functional thermo chemistry. III. The role of exact exchange. Journal of Chemical Physics, 98: 5648-5652.

Casida, M. E. and Chong, D. P. (eds.) (1995). Recent Developments in Density Functional Theory. World Scientific, Singapore, 1: 155.

Casida, M. E.; Casida, K. C. and Salahub, D. R. (1998). Excited-state potential energy curves from time-dependent density-functional theory: A cross section of formaldehyde's 1A1 manifold, International Journal of Quantum Chemistry, 70 (4-5): 933-941.

Condon, M. E.; Brady, T. E.; Feist, D.; Malefyt, T.; Marc, P.; Quakenbush, L. S. et al., (1993). Brighton Crop Prot. Conf. Weeds, BCPC Publications, Alton, Hampshire, England, pp. 41-46. 
Frisch, A.; Nielson, A. B. and Holder, A. J. (2000). Gauss View User Manual, Gaussian Inc, Pittsburgh, P.A.

Frisch, M. J.; Trucks, G. W.; Schlegel, H. B.; Scuseria, G. E.; Cheeseman, J. R.; Robb, M. A. et al. (2009). GAUSSIAN 09, Revision, Gaussian Inc. Wallingford, CT.

Hohenberg, P. and Kohn, W. (1964). "Inhomogeneous Electron Gas", Physical Review B, 136: 864-871.

Khidre, R. E. and Abdel-Wahab, B. F. (2013). Application of Benzoylaceteonitrile in the Synthesis of Pyridines Derivatives, Current Organic Chemistry, 17 (2): 1-16.

Lee, C. T.; Yang, W. and Parr, R. G. (1988). "Development of the Colle-Salvetti correlation-energy formula into a functional of the electron density". Physical Review B, 37 (2): 785-789.

Lewis, D. F. V.; Ioannides, C. and Parke, D. V. (1994). Interaction of a series of nitriles with the alcohol-inducible isoform of P450: Computer analysis of structure-activity relationships, Xenobiotica, 24 (5): 401-408.

Maeno, S.; Miura, I.; Masuda, K. and Nagata, T. (1990). Brighton Crop Protection Conference on Pests and Diseases, BCPC Publications, Alton, Hampshire, England, pp. 415-422.

Martin, J. M. L. and Aslenoy, C. V. (1995). Gar2ped. University of Antwerp. Belgium.
Medjani, M.; Hamdouni, N.; Brihi, O.; Boudjadaa, A. and Meinnel, J. (2015). Crystal structure of 4 , 6-dichloro-5-Methylpyrimidine, ActaCryst E (crystallographic communication), $\mathbf{7 1}$ : 01073-01074.

Mishra, R.; Joshi, B. D.; Srivastava, A.; Tandon, P. and Jain, S. (2014). Quantum chemical and experimental studies on the structure and vibrational spectra of an alkaloid-Corlumine, Spectrochimica Acta A, 118: 470-480.

Parr, R. G. and Yang, W. (1989). Density Functional Theory of Atoms and Molecules. Oxford University Press, New York. Oxford, pp 333.

Selby, T. P.; Drumm, J. E.; Coats, R. A.; Coppo, F. T.; Gee, S. K.; Hay, J. V.; et al. (2002). Synthesis and Chemistry of Agrochemicals, ACS Symposium Series, American Chemical Society, Washington DC, 800: 74-84.

Srivastava, A.; Mishra, R.; Tandon, P. and Bansal, A. K. (2013). FT-Raman, FT-IR, UV spectroscopic, NBO and DFT quantum chemical study on the molecular structure, vibrational and electronic transitions of clopidogrel hydrogen sulfate form 1: A comparison to form 2, Spectrochimica Acta A, 104: 409-418.

Yoshida, H.; Takeda, K.; Okamura, J.; Ehara, A. and Matsurra, H. (2002). A New Approach to Vibrational Analysis of Large Molecules by Density Functional Theory: Wave numberLinear Scaling Method, Journal of Physical Chemistry A, 106: 3580-3586. 